\title{
ASSESSING THE ACTUAL SIZE DISTRIBUTION OF ATMOSPHERIC AEROSOLS COLLECTED WITH A CASCADE IMPACTOR
}

\author{
L. Gomes, G. Bergametti, F. Dulac* and U. Ezat* \\ Laboratoire de Physico-Chimie de l'Atmosphère, UA-CNRS 717, Université Paris 7, 2, Place Jussieu, 75251 \\ Paris Cedex, France \\ *Centre des Faibles Radioactivites, Laboratoire mixte CNRS-CEA, Domaine du CNRS, 91198 Gif-sur-Yvette \\ Cedex, France
}

(Received 3 April 1989; and in final form 25 July 1989)

\begin{abstract}
A set of elemental mass-particle size distributions is obtained from a low volume cascade impactor whose characteristics are discussed. The data processing used [Puttock's data inversion fitting technique; Puttock, J. S. (1981) Atmos. Envir. 15, 1709], shows that bounce-off can severely affect the interpretation of data when the ambient aerosol presents a coarse mode of dust particles $(D>2 \mu \mathrm{m})$. This study proposes an improvement of the fitting method, for correcting experimental mass-particle size distributions for these particle bouncing effects when usual preventive procedures cannot be applied. The bounce-off contribution to the final filter of the impactor could be estimated by a microscopic examination and compared to the one predicted by the method developed in this work.
\end{abstract}

\section{INTRODUCTION}

Up to now, in order to connect chemical composition of atmospheric particles with their mass-size distribution, cascade impactors have been the most useful instruments. These cascade impactors select the particles as a function of their inertial properties. Different stages, stacked in order to generate an increase in the air-flow velocities, collect the particles in decreasing class sizes.

The estimation of continuous elemental mass-size distributions of the sampled aerosol is based on multi-elemental analysis of the matter collected on each individual stage (Sadavisan, 1978; Maenhaut et al., 1983; Pacyna et al., 1984). Hence, the determination of size distributions requires the knowledge of the collection characteristics of the impactor used (i.e. the collection efficiency curves of the different stages as a function of a particle size), including the main mechanisms of non-ideal behaviour such as cross-sensitivity, wall losses and particle bounce-off.

The collection characteristics of existing cascade impactors are far from ideal step functions (Rao and Whitby, 1978; Knuth, 1979). In particular, the collection efficiency of each stage varies between 0 and $100 \%$ over a relatively large particle size range. This leads to the mixing, in various proportions, of particles which can exhibit relatively different sizes on one stage. Moreover, previous studies have shown that wall loss and bounce-off effects can be severe for hard, dry alumino-silicate particles (Wesolowski, 1973; Buat-Ménard et al., 1983). Total wall losses are generally presented as a function of a particle size, surface properties of the particles, or sampling time. They can represent up to $30-40 \%$ of the total elemental concentration (Ondov et al., 1978). Hence, to validate the mass-size distribution parameters obtained from impactor measurements, a wall loss approximation, expressed as a function of particle size, is generally added to the stage efficiency curves (Rao and Whitby, 1978; Mitchell, 1988).

Various workers (Wesolowski, 1973; Dzubay et al., 1976; Walsh et al., 1978; Buat-Ménard et al., 1983) have reported that bounce-off and re-entrainment can also affect the representativity of the sampling. Most of them suggest that this error can be minimized by the application of an adhesive agent to the impaction surfaces. However, when samples are to be analysed for chemical composition, this application is generally not compatible with low blank values which are necessary for accurate trace analyses. Moreover, in sampling with 
high particle concentrations, successively deposited layers of particles render the coating relatively ineffective. Other authors (Burton et al., 1973; Walsh et al., 1978) propose to reduce particle bouncing by using glass fibre filters or cellulose fibre filters. Unfortunately, those filters where particles could be trapped in the fibre, may not well suit such an analytical procedure as the X-ray fluorescence (XRF) technique or scanning electron microscopy (SEM), as both require a smooth flat collection surface.

In this study, using a set of elemental mass-particle size distributions obtained by a data inversion fitting technique from low volume cascade impactor samples on Nuclepore filters, we show that bounce-off can severely affect the interpretation of data when the ambient aerosol presents a coarse mode of dust particles $(D>2 \mu \mathrm{m})$. We propose an improvement of Puttock's (1981) inversion method for correcting experimental mass--particle size distributions for these particle bouncing effects.

\section{EXPERIMENTAL}

Aerosol samplings were carried out with a model EGAI 80, low volume, cascade impactor (Bergametti et al., 1982) which was operated at the nominal flow rate of $1 \mathrm{~m}^{3} \mathrm{~h}^{-1}$. The EGAI 80 impactor is a single-jet, circular cascade impactor with five stages and a final back-up filter. Its body is in Nylatron (nylon + graphite) in order to minimize contamination due to metals and electrostatic attraction. Nuclepore $0.4 \mu \mathrm{m}$ pore size filters were used as particle impaction surfaces on the five impactor stages and for the final back-up filter. The latter has a reported collection efficiency of more than $90 \%$ for $0.1 \mu \mathrm{m}$ diameter particles. This kind of impactor allows the collection of aerosol particles within the $0.1-25 \mu \mathrm{m}$ size range. Due to the entry characteristics of the device the largest particles are not aspirated.

Using this sampler, several workers have obtained aerosol concentration data as a function of particle size for $\mathrm{Na}, \mathrm{Al}, \mathrm{Si}, \mathrm{P}, \mathrm{S}, \mathrm{K}, \mathrm{Ca}, \mathrm{Ti}, \mathrm{Mn}$ and $\mathrm{Fe}$ at different locations corresponding to different environments: the industrial complex of Fos/Mer close to the French Mediterranean shore (Gomes et al., 1988) and an iron and steel works located in the iron-basin of Lorraine, France (Ebner, 1984); a coastal site along the Atlantic Ocean in Brittany, France (Marchal, 1983) and another one along the Mediterranean Sea in Corsica which can be exposed to southern continental air masses from north Africa (Bergametti, 1987); and a desert location in the northern Sahara (Gomes, unpublished results). The sampled air volume was variable as a function of the duration of sampling (up to $24 \mathrm{~h}$ ) and was measured with a Gallus volume-counter. From these data, mass-particle size distributions of elements, selected to be representative of different aerosol sources, will be presented here.

Except for $\mathrm{Na}$, chemical analyses were performed by wavelength dispersive X-ray fluorescence spectrometry (CGR alpha 10) according to the method described by Losno et al. (1987) using an X-ray tube with $\mathrm{Cr}$ or $\mathrm{W}$ targets. The collected samples were used directly in the spectrometer without any further preparation. Each sample was counted twice using a proportional gaseous flux detector and the $K_{\alpha}$ ray of each analysed element. Total counts were corrected for blank filter counts, and analytical precision was better than $7 \%$ for every element analysed (Bergametti, 1987).

Sodium analyses were performed by instrumental neutron activation. This procedure involved irradiating the sample in a thermal neutron flux of $10^{14} \mathrm{n} \mathrm{cm}^{-2} \mathrm{~s}^{-1}$ for $2 \mathrm{~min}$ in the research reactor OSIRIS of the Centre d'Etudes Nucléaires at Saclay, France. The samples were then counted on a $\mathrm{Ge}(\mathrm{Li})$ detector. Elemental calibration was made with elemental synthetic standards prepared in the laboratory. Results have been corrected for blanks and the mean statistical errors for neutron activation analyses were generally less than $10 \%$ for $\mathrm{Na}$ (Marchal, 1983).

\section{IMPACTOR CHARACTERISTICS}

\section{Impactor response function}

An ideal impactor stage, $i$, would have the collection efficiency $E_{i}(D)$ as a function of particle aerodynamic diameter, $D$, defined by $E_{i}(D)=1$ for $D>D_{50, i}$ and $E_{i}(D)=0$ for 
$D<D_{50, i}$ where $D_{50, i}$ is the $50 \%$ aerodynamic equivalent cut-off diameter of the considered stage (i.e. the value of $D$ for which the collection efficiency of the particular stage is equal to $50 \%$ ). Significant differences from the ideal step function are shown in Fig. 1, which presents the actual stage efficiency functions for our impactor. Indeed, it appears that particles of a given diameter can be distributed between several stages. These response functions have been experimentally determined in a previous study of calibration by Bergametti et al. (1982). We fitted them, assuming that every impactor stage has a response function approximated by a cumulative log-normal distribution (Kubie, 1971). For each impaction stage $i$, this function $E_{i}$ can be expressed by:

$$
E_{i}\left(D, D_{50, i}, \sigma_{c, i}\right)=\frac{1}{2}+\frac{1}{2} \operatorname{erf}\left(\left(\log D-\log D_{50, i}\right) / \sqrt{2} \sigma_{c, i}\right)
$$

where $\sigma_{c, i}$ is the $\log$ geometric S.D. for the stage $i$. Consequently, the response function of each stage is completely specified by two significant parameters (i.e. $D_{50}$ and $\sigma_{c}$ ). The parameters for each stage of the EGAI 80 impactor when it is operated in the calibration conditions at a flow rate of $161 \mathrm{~min}^{-1}$ for particles of $2.2 \mathrm{~g} \mathrm{~cm}^{-3}$ density are given in Table 1 .

These experimental cut-off diameters agree well with the theoretical formulation given by Marple (1970):

$$
D_{\text {eff }}^{2}=\frac{0.135 \pi \mu W^{3} \sqrt{\text { eff }}}{Q \rho(1-\sqrt{\text { eff }})}
$$

where $D_{\text {eff }}$ is the cut-off diameter for the efficiency eff, $\mu$ is the air viscosity, $W$ is the jet width, $Q$ is the flow rate and $\rho$ is the particle density. For a given stage, the cut-off diameter appears to be a function of $Q$ and $\rho$. Therefore, the values of $D_{50, i}$ were corrected according to the

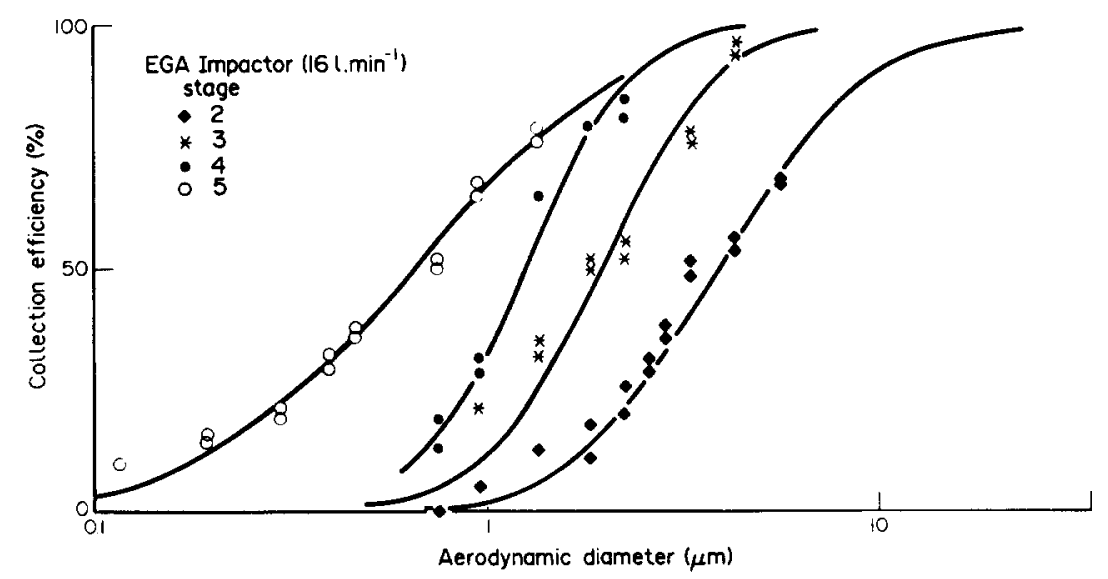

Fig. 1. Stage collection efficiency as a function of particle size for the EGAI 80 impactor. Symbols represent the experimental calibration by Bergametti et al. (1982). The response functions are fitted to a cumulative log-normal distribution according to parameters given in Table 1.

Table 1. Fifty percent aerodynamic equivalent cut-off diameter and $\log$-geometric S.D. for each stage of the EGAI impactor $(Q$

\begin{tabular}{lcl}
\multicolumn{2}{c}{$\left.=161 \mathrm{~min}^{-1} ; \rho=2.2 \mathrm{~g} \mathrm{~cm}^{-3}\right)$} \\
\hline Stage & $D_{\text {so }}(\mu \mathrm{m})$ & $\sigma_{\mathrm{c}}$ \\
\hline 1 & $8.75^{*}$ & $0.23^{*}$ \\
2 & 3.90 & 0.31 \\
3 & 1.95 & 0.25 \\
4 & 1.25 & 0.22 \\
5 & 0.65 & 0.44 \\
\hline
\end{tabular}

*Estimated from Marple (1970).
Table 2. Ratios of the total elemental concentrations collected by an impactor with those simultaneously collected on a total filter

\begin{tabular}{lccc}
\hline Element & $\begin{array}{c}\text { Mean } \\
\text { ratio }\end{array}$ & S.D. & $\begin{array}{c}\text { Number of } \\
\text { samples }\end{array}$ \\
\hline $\mathrm{Al}$ & 0.97 & 0.13 & 11 \\
$\mathrm{Si}$ & 0.96 & 0.10 & 11 \\
$\mathrm{P}$ & 0.98 & 0.09 & 7 \\
$\mathrm{~S}$ & 1.17 & 0.09 & 11 \\
$\mathrm{~K}$ & 0.89 & 0.15 & 11 \\
$\mathrm{Ca}$ & 0.97 & 0.18 & 11 \\
$\mathrm{Ti}$ & 0.94 & 0.14 & 9 \\
$\mathrm{Mn}$ & 0.88 & 0.12 & 5 \\
\hline
\end{tabular}


mean flow rate during sampling. On the other hand, we assumed the density of the collected particles to be close to the density of calibration $\left(2.2 \mathrm{~g} \mathrm{~cm}^{-3}\right)$. Finally, the theory of Marple allowed us to obtain values for stage 1 which could not be tested experimentally (Bergametti et al., 1982).

Wall losses

Our cascade impactor sampler was designed to minimize wall losses. Indeed, unlike the multi-jet cascade impactors for which the ratio of wall to jet area is large, the EGAI 80 model is a single-jet sampler and has a more direct aerosol pathway. Moreover, its Nylatron walls are not subject to the retention of particles.

Estimates of wall and interstage losses for cascade impactors are generally made by comparing total element concentrations collected by the impactor with those simultaneously collected on a total filter at the same location (Dzubay et al., 1976; Ondov et al., 1978). This comparison was made during a sampling period in Corsica (Table 2). Taking into account analytical uncertainties, the average elemental collection efficiency of the impactor, relative to the total filter, was assumed to be equal to one. The use of such an impactor sufficiently minimizes the effects of wall losses so that a specific correction is not required.

\section{Bounce-off}

Considering the impactor stage collection efficiencies, the proportion of particles of aerodynamic diameter $D$ reaching the back-up filter is theoretically described by:

$$
F_{\text {back-up }}(D)=\prod_{i=1}^{5}\left[1-E_{\mathrm{j}}(D)\right]
$$

Hence, this transmission efficiency through stages 1-5 gives the back-up response function of the impactor. This function, which is drawn in Fig. 2 for an impactor running at $111 \mathrm{~min}^{-1}$, becomes $<0.002$ for particles larger than $3 \mu \mathrm{m}$ in diameter. Nevertheless, SEM examinations of some back-up filters revealed the presence of many mineral particles which are more than $3 \mu \mathrm{m}$ in diameter (Fig. 3), hence, bounce-off can be suspected. In the situation where the conventional methods for reducing particle bounce may interfere with the chemical analytical techniques and consequently cannot be used, a mathematical correction procedure has to be envisaged.

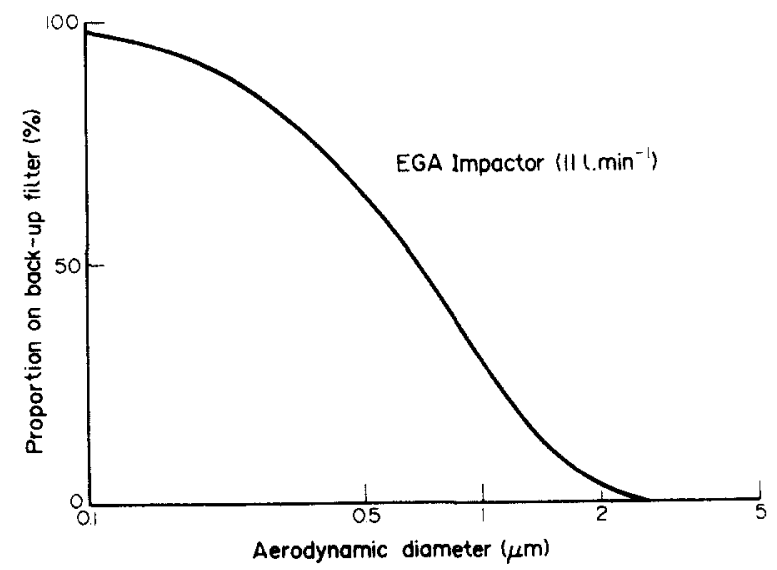

Fig. 2. Back-up response function for an EGA Impactor. 

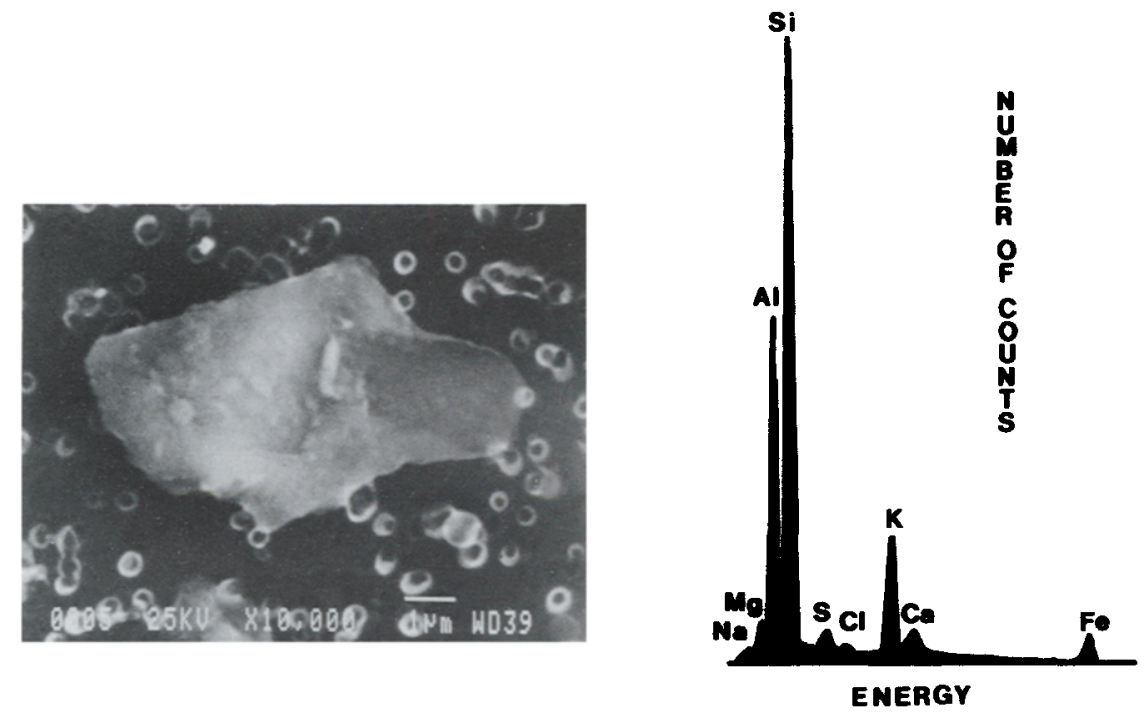

Fig. 3. SEM photograph and $\mathrm{X}$-ray spectrum of a large alumino-silicate particle from a portion of filter collected in northern Sahara (SA-IMP1). 


\section{SIZE DISTRIBUTION INVERSION TECHNIQUE}

All of the above considerations suggest that concentration data from the impactor stages need to be processed in such a way as to take into account the non-ideal response characteristics of the impactor when determining continuous elemental mass-particle size distributions.

In order to consider the effect of cross-sensitivity, it is necessary to invert the data of cascade impactors by an appropriate method. We used the data inversion technique described by Puttock (1981) which fits a sum of log-normal distributions to impactor data. Puttock's computational scheme converts stage loadings to size distribution using the detailed response functions of the impactor. This technique involves the calculation of the expected stage loadings from an assumed aerosol distribution and the impactor characteristics. Then, we compare the expected values with the measured values.

In our procedure, the measured mass-size distributions were expressed in the form $\mathrm{d} M / \mathrm{d}(\log D)$. They were then fitted to monomodal or bimodal distributions, each mode being log-normal:

$$
\frac{\mathrm{d} M}{\mathrm{~d}(\log D)}=\sum_{j=1}^{n} \frac{M_{j}}{\sqrt{2 \pi} \log \sigma_{j}} \quad \exp \frac{\left(\log D-\log M M D_{j}\right)^{2}}{-2 \log ^{2} \sigma_{j}}
$$

with $M_{j}$ the mass fraction of particles for mode $j, M M D_{j}$ the mass median diameter of the distribution and $\sigma_{j}$ its geometric S.D. The EGAI 80 impactor provides only six data: the mass on the five stages and on the back-up filter. As each mode is characterized by three parameters (mean, S.D. and amplitude), the number of modes which can be fitted is limited to two $(n \leqslant 2)$.

The tropospheric particle size distributions are now usually reported as multimodal distribution functions (Jaenicke, 1985). However, within the size range investigated $(0.1-25 \mu \mathrm{m})$, the monomodal nature of the mass-size distribution has been widely emphasized for various types of aerosol (Whitby, 1978; Gillette, 1980; d'Almeida and Schütz, 1983; Shaw, 1986; Bergametti, 1987; Gomes et al., 1988; Dulac, 1989). The use of log-normal modes for fitting particle size data has been extensively justified by various workers (Jaenicke, 1985; Giorgi, 1988) and is often used to describe particle mass-size spectra of asymmetric shape, for particles from industrial emissions (Sverdrup, 1978) as well as from the maritime (Dulac et al., 1989) or desert atmospheres (Patterson and Gillette, 1977).

This approach is particularly sensitive to errors in measurements or in specification of the instrument characteristics (Cooper, 1976). We assumed the quality of the final fit to be good, when as much of the collected material as possible is accounted for by the fitted log-normal distribution, the relative difference between expected and measured values of stage loadings is within the range of analytical uncertainty. The resulting aerosol particle size distribution is accepted as a solution for the inversion problem. A chi-square test was then applied to determine the minimum deviation of the measured distributions from a monomodal or bimodal log-normal distribution. However, we were not able to compute a level of significance of the fit since the distribution parameters were estimated from mass distributions and not from number distributions.

\section{RESULTS}

Some examples of measured mass-size distributions of elements assumed to be characteristic of the aerosol sampled in the different locations are shown in Fig. 4. The short-dashed line represents the observed mass-size distribution in terms of relative stage loading per unit of log-diameter scale. The long-dashed line corresponds to the computed stage loadings resulting from an aerosol distributed according to the log-normal distribution obtained by the fitting procedure described above. These distributions are normalized so that the integral of the histogram in a given size range represents the percentage of mass in this size range. The aerosol distribution, whose parameters are provided by the data inversion procedure, is shown by the solid line. In summary, the long-dashed line depicts the discrete partitioning of 


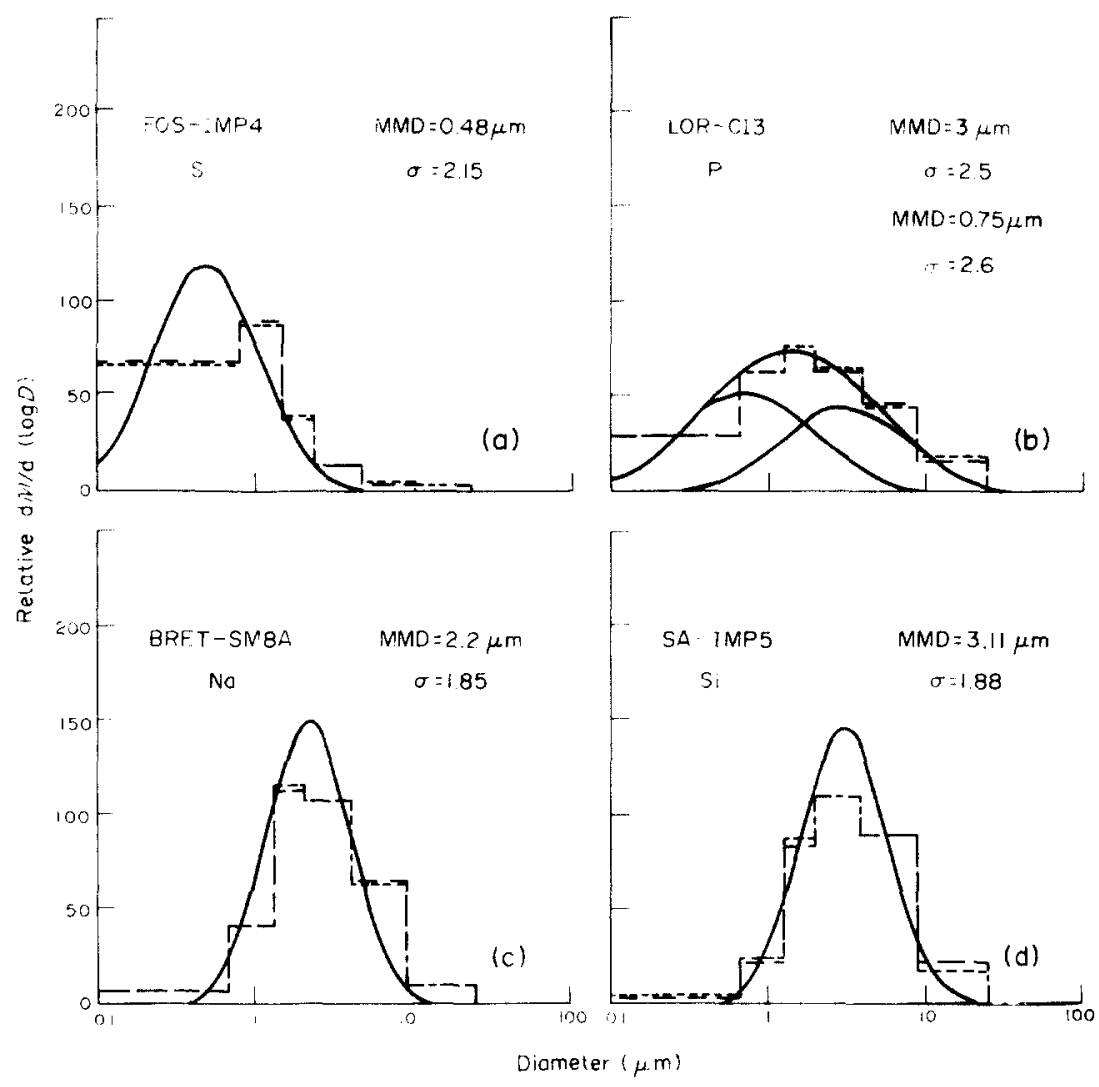

Fig. 4. The $\mathrm{d} M / \mathrm{d}(\log D)$ plot of the measured stage loadings (short-dashed line), the fitted stage loadings (long-dashed line) and the fitted continuous monomodal or bimodal log-normal distribution (solid line), determined for elements at different locations: (a) $S$ in industrial area, Fos/Mer, France; (b) $\mathrm{P}$ in steelwork, Lorraine, France (each mode + sum); (c) $\mathrm{Na}$ in coastal region, Brittany, France and (d) Si in desert region, northern Sahara.

this distribution through the different stages of an ideal impactor. The short-dashed line depicts the experimental partitioning.

In the industrial area of Fos/Mer, S (Fig. 4a) primarily results from anthropogenic emissions. These particles, which come from gas-to-particle conversions, form the accumulation mode $(<2 \mu \mathrm{m})$ according to the classical scheme of Whitby (1973). This conversion process is similar for the fine fraction of $P$ collected in the steelwork of Lorraine (Fig. $4 \mathrm{~b}$ ). In this sample, a coarse mode is also observed. It is attributed to the mechanical production of aerosol particles during the handling of the Fe ore (Ebner, 1984).

The other elements considered in this figure originate from natural sources. In coastal regions, Na concentrations (Fig. 4c) are mainly attributed to marine aerosol. The production of such a sea salt-derived element generally results from a bubble bursting at the sea surface (Blanchard, 1963). In continental regions, the production of crustal aerosols occurs through the mechanical disintegration of the soil material by wind erosion (Gillette, 1980). The distribution of $\mathrm{Si}$, which is the major element in desert aerosol, is presented in Fig. 4d.

The main observation which results from Fig. 4 is that the log-normal distributions of aerosol computed in various situations are most often indistinguishable from the observed stage loadings. This result confirms the reliability of the log-normal fit for the distribution function of collected aerosols. However, in the case of $\mathrm{Si}$ in desert aerosol, a slight overprediction in larger particles coupled with an underestimation in smaller particles can be observed. This type of deviation from a log-normal distribution was systematically found for elements contained in alumino-silicate particles, suggesting some bouncing could have occurred during the sampling of atmospheric aerosol of dominantly crustal origin (see Fig. 3). 


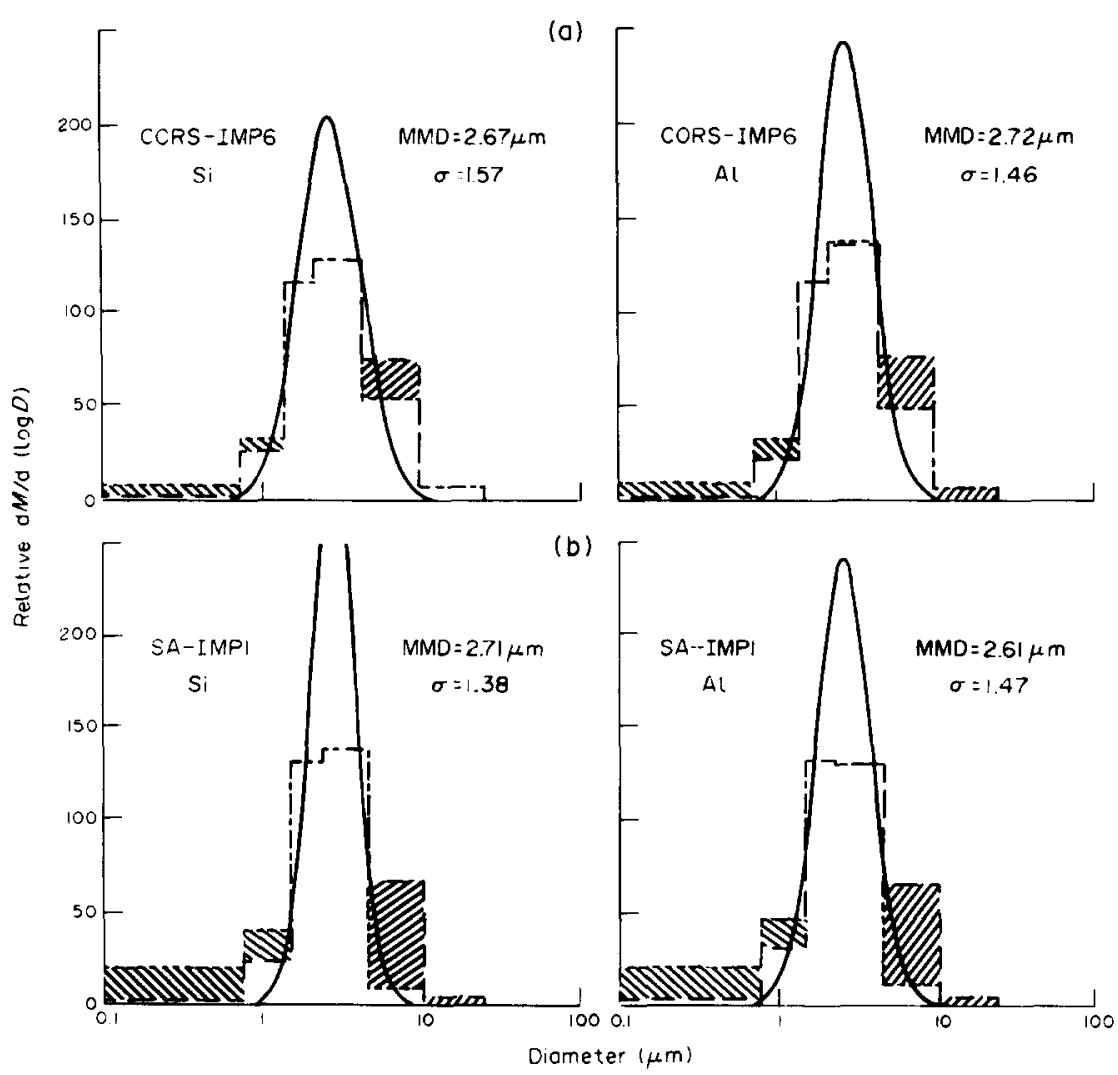

Fig. 5. Caption as Fig. 4 for major elements $(\mathrm{Al}, \mathrm{Si})$ included in alumino-silicate particles having a continental origin: (a) Corsica and (b) northern Sahara. The dashed area shows the deviation to the log-normal distribution (observed stage loading, in excess: $\backslash / \backslash$ and deficient: $/ / /$ ).

The mass-size distribution of major elements ( $\mathrm{Al}, \mathrm{Si})$ which are included in aluminosilicate particles collected on two sites are shown in Fig. 5: Corsica (Fig. 5a) and northern Sahara (Fig. 5b). The sampling in Corsica was carried out during a dust event of African origin, and the Saharan sample corresponds to a sampling period different from the one presented in Fig. 4d. In both cases, a large deviation from the log-normal distribution was observed, if one assumed a monomodal distribution. Hence, the existence of a bimodal distribution had to be investigated. However, as particle bounce-off was suspected, and since its effects mainly result in displacement of the largest particles to the smallest size range stages, the discrepancies to the log-normal distribution could also be attributed to bouncing. Over-prediction of large particles could then result from a deficiency in the collection efficiency due to bouncing, and consequently underestimation observed in smaller size range stages would be explained by an excess of large particles having bounced from previous stages.

Bounce-off can be estimated by assuming that the difference observed in larger particles, between input and fitted distributions, can be balanced by the difference observed in finer particles. This hypothesis constitutes an additional relationship between the different parameters. This can be expressed by:

$$
\sum_{i=1}^{n}\left(C_{i}-M_{i}\right)=\sum_{i=m}^{6}\left(M_{i}-C_{i}\right)
$$

with $1 \leqslant n \leqslant 5$ and $n<m \leqslant 6$, and where $M_{i}$ represents the fraction of mass measured on stage $i$ and $C_{i}$ the relevant computed stage loading (with back-up filter represented by $i=6$ ). In order to treat all the available cases, we have generalized an empirical equation in which $n$ $=2$ and $m=5$. This represents the most frequently observed case. This most frequent case 
leads us to a generally satisfactory solution in explaining the transfer of material between stages due to bouncing.

\section{VALIDATION}

The 'bounce-off relationship' (equation 5) was tested to account for the discrepancies of the observed distribution to the fitted monomodal log-normal distribution. This distribution, corrected using equation (5), was compared to a bimodal distribution not involving bouncing. The presence of a second finer mode could also explain the fraction of mass collected on the back-up filter. The comparison between both these kinds of distribution was possible by calculating the chi-square value of each of them since the number of degrees of freedom was the same.

In all the cases tested, the solution which consisted of including a bounce-off relationship provided a chi-square value lower by about two orders of magnitude than a bimodal solution without bouncing effect. For instance, Table 3 lists the results obtained for $\mathrm{Si}$ in the sample 'CORS-IMP6' presented in Fig. 5a. This table gives the relative stage loading for both the experimental measurements and the best fitted distribution. For the monomodal distribution, it provides the values of the fractions having bounced, which are estimated by the difference between the experimental and fitted measurements (to within $0.1 \%$ ). These estimations, which follow equation (5), are counted negative when a loss from a given stage is suspected, and positive for an excess of particles having bounced from previous stages. The statistical parameters, including the chi-square value, are also given in Table 3 . Concerning the monomodal fit, the chi-square value is calculated from the corrected distribution. The relevant monomodal and bimodal fitted distributions are drawn, respectively, in Fig. 6a and b. These results show that equation (5), together with a monomodal distribution fit, not only explain the impactor data better than does a bimodal distribution fit, but also that the bimodal solution drawn in Fig. $6 \mathrm{~b}$ is obviously unrealistic.

Hence, the distributions presented in Fig. 5 appear to be the best available solutions. The dashed area indicates the displacement of fraction of mass from larger to smaller size stages. In the retained solution, and according to equation (5), the fraction of mass in excess on small size stages is well balanced by that lacking on the large size stages (for example: $7.15 \%$ for CORS-IMP6, 21\% for SA-IMP1, see Table 3 and Fig. 5). The bounce-off contribution to the back-up filter could be estimated by a microscopic examination and compared to the one predicted by the method developed above.

Scanning electron microscopy and associated electron microprobe analysis (SEM-EMP) were performed on a portion of the 'SA-IMP1' back-up filter. The sample of about $1 \mathrm{~cm}^{2}$ was

Table 3. Results of the test for different fittings applied to the sample 'CORS-IMP6' (see Fig. 6 for relevant plots and text for explanations)

\begin{tabular}{lclc}
\hline & \multicolumn{3}{c}{ Stage loading $(\%)$} \\
\cline { 2 - 4 } Stage & $\begin{array}{c}\text { Experimental } \\
\text { measurement }\end{array}$ & $\begin{array}{c}\text { Monomodal }{ }^{*} \\
\text { (deduced bounce) }\end{array}$ & Bimodal $^{+}$ \\
\cline { 2 - 4 } 1 & 3.3 & $3.2(-0)$ & 3.0 \\
2 & 18.9 & $26.1(-7.2)$ & 20.3 \\
3 & 38.6 & 38.5 & 36.8 \\
4 & 22.3 & 22.2 & 23.2 \\
5 & 9.3 & $7.5(+1.9)$ & 8.9 \\
6 & 7.6 & $2.5(+5.2)$ & 7.8 \\
\hline
\end{tabular}

* $M=100 \% ; M M D=2.67 \mu \mathrm{m} \pm 0.01 ; \sigma=1.57 \pm 0.01$ and $x^{2}=0.006$.

$M_{1}=38.5 \% \pm 0.5 ; M M D_{1}=1.78 \mu \mathrm{m} \pm 0.01 ; \sigma_{1}=2.90$ $\pm 0.01 ; \quad M_{2}=61.5 \% \pm 0.5 ; \quad M M D_{2}=2.51 \mu \mathrm{m} \pm 0.01 ; \quad \sigma_{2}$ $=1.03 \pm 0.01$ and $\chi^{2}=0.28$ 


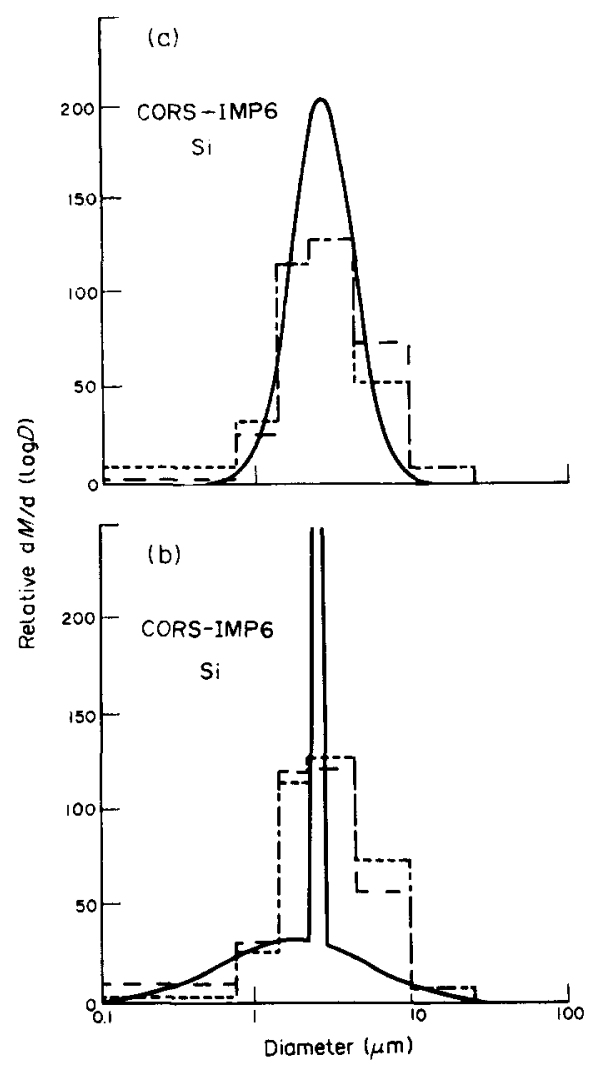

Fig. 6. Caption as Fig. 4. Result of test for Si element in the sample 'CORS-IMP6': (a) monomodal fit and (b) bimodal fit (see Table 3 for relevant data).

coated with a layer of graphite and examined using a JEOL model JSM 840 electron microscope coupled with an EDAX spectrometer according to the process described by Buat-Ménard et al. (1983). A total area of $0.271 \mathrm{~mm}^{2}$ was scanned in order to determine the mass fraction of particles larger than $3 \mu \mathrm{m}$ in diameter as those shown in Fig. 3. Indeed, the analysis of Fig. 2 shows that the presence of such large particles is likely to be due to bounce from previous impaction stages. A grand total of 120 different mineral particles were analysed in this size range using a magnification of 5000 times. The total mass of particles larger than $3 \mu \mathrm{m}$ in diameter counted on the final filter was calculated according to Buat-Ménard et al. (1983), using the area-equivalent diameter (equal to $2 \sqrt{\text { cross-sectional area } / \pi)}$ and assuming a hemispherical shape for these particles, an average density of $2.2 \mathrm{~g} \mathrm{~cm}^{-3}$ and a homogeneous deposition on the filter. The total amount of large particles found on the final filter and attributed to bounce from previous stages was estimated to be about $18.1 \mu \mathrm{g}$.

This calculation was next compared to the estimation provided by the difference between the experimental distribution from the impactor and the fitted distribution. In the case of the desert aerosol sample presented in Fig. 5b, the applied correction indicates that $90.5 \%$ of the particles measured on the back-up filter result from bounce-off. The total mass of dust having bounced on the final filter was therefore calculated from $\mathrm{Al}$ and $\mathrm{Fe}$ measurements, assuming that the $\mathrm{Al}$ and $\mathrm{Fe}$ contents of mineral dust are $8 \%$ (Buat-Ménard et al., 1983) and $5.4 \%$ (Chester and Stoner, 1974) by weight, respectively. This calculation gives a total bounce-off on back-up filter estimate of between 17.3 and $20.5 \mu \mathrm{g}$.

Despite large uncertainties in the method, a remarkably good agreement between estimated bounce-off deduced by microscopy and estimated bounce-off calculated by fitting is obtained. This result strongly suggests that the magnitude of bounce-off is responsible for the deviation observed between experimental data and log-normal distribution fit. 


\section{CONCLUSIONS}

From the aerosol data collected by a low-volume cascade impactor at different locations and for different types of sources, it was shown that in most cases each population of the elemental mass size distribution can be assimilated to a log-normal distribution by using a data inversion procedure. However, large deviations between input data and log-normal distribution exist for dry alumino-silicate particles. The data processing applied in this work showed that this discrepancy from the log-normal distribution is due to bounce-off effects.

Indeed, one can consider that bounce-off and re-entrainment onto the back-up filter is appreciably reduced for small particles $(<2 \mu \mathrm{m})$ which come from gas-to-particle conversions and form a submicron size mode, and are hence not subject to bouncing. The same observation can be noted for marine aerosol, represented by $\mathrm{Na}$, which presents nevertheless a MMD between 2 and $3 \mu \mathrm{m}$. The study of Walsh et al. (1978) suggests that the hygroscopic nature of sea salt particles reduces their potential for bouncing, and the high relative humidity of marine air may also moisten the filter, thereby providing a more efficient impaction surface. On the other hand, in the case of aerosol of dominantly crustal origin, bouncing due to the inability of dry solid particles to adhere to dry impaction surfaces was highlighted. Indeed, this bounce effect has been reported in aerosol sampling of dust particles by cascade impactor (Walsh et al., 1978; Buat-Ménard et al., 1983). For example, in the case of desert aerosol presented in Fig. 5, the applied correction indicates that particles observed on the back-up filter primarily result from bounce-off, while the mass loading observed on stage 2 is under-estimated by a factor of seven

This study proposes a mathematical procedure to estimate this bounce when the usual methods used to minimize it, such as the application of an adhesive agent to the impaction stages or the use of glass or cellulose filters, cannot be applied. The parameters of the distributions (MMD and $\sigma$ ) can be given for corrected distributions which take into account the bouncing effect. Hence, for the continental aerosols, the elemental MMD values obtained by fitting to a log-normal distribution according to the inversion technique are higher than those obtained by other investigators, while S.D.s are lower. For example, the sample presented in Fig. Sa has an Al MMD and S.D. of $2.72 \mu \mathrm{m}$ and 1.46, respectively, compared to values of 2.25 and $2.10 \mu \mathrm{m}$ calculated without correction for bouncing (Bergametti, 1987). According to Dulac et al. (1989), such differences in the retrieved parameters, especially in S.D., are likely to generate large differences in the apparent dry deposition velocity of particles, as calculated from a dry deposition model. Therefore, this fitting procedure allows the determination of mass-particle size distribution parameters, corrected for the usual errors due to bounce-off by estimating the contribution of large particles, which result from this re-entrainment phenomenon, to smaller size stages.

\section{REFERENCES}

Bergametti, G. (1987) Thèse d'état. University of Paris 7.

Bergametti, G., Vie Le Sage, R., Grubis, B., Dulieu, B. and Elichegaray, C. (1982) Environ. Tech. Lett. 3, 297. Blanchard, D. C. (1963) in Progress in Oceanography (Edited by Sears, M.), Vol. I, p. 71. Oxford.

Buat-Ménard, P., Ezat, U. and Gaudichet, A. (1983) in Precipitation Scavenging, Dry Deposition, and Resuspension (Edited by Pruppacher, H. R.), Vol. II, p. 1259. Elsevier, Amsterdam.

Burton, R. M., Howard, J. N., Penley, R. L., Ramsay, P. A. and Clark, T. A. (1973) J. Air Pollut. Ass. 23, 277.

Chester, R. and Stoner, J. H. (1974) Mar. Chem. 2, 157

Cooper, D. W. (1976) Am. ind. Hyg. Assoc. J. 37, 622.

d'Almeida, G. A. and Schütz, L. (1983) J. Climate appl. Meteorol. 22, 233.

Dulac, F., Buat-Ménard, P., Ezat, U., Melki, S. and Bergametti, G. (1989) Tellus 41B, 362.

Dzubay, T. G., Hines, L. E. and Stevens, R. K. (1976) Atmos. Environ. 10, 229.

Ebner, P. (1984) Thesis. University of Paris 7.

Gillette, D. (1980) Ann. N.Y. Acad. Sci. 338, 348.

Giorgi, F. (1988) Tellus 40B, 23.

Gomes, L., Bergametti, G., Chatenet, B. and Dutot, A. L. (1988) Environ. Tech. Lett. 9, 721.

Jaenicke, R. (1985) in Numerical Data and Functional Relationships in Science and Technology (Edited by Fisher, G.) Vol. 4b, pp. 391-457. Springer, Berlin.

Knuth, R. H. (1979) Report of the Environmental Measurement Laboratory, National Technical Information Service, U.S. Dept. of Commerce, Springfield, VA.

Kubie, G. (1971) J. Aerosol Sci. 2, 23. 
Losno, R., Bergametti, G. and Mouvier, G. (1987) Environ. Tech. Lett. 8, 77.

Maenhaut, W., Raemdonck, H., Selen, A., Van Grieken, R. and Winchester, J. W. (1983) J. Geophys. Res. $88,5353$.

Marchal, T. (1983) Thesis. University of Paris 7.

Marple, V. A. (1970) Ph.D. Thesis. University of Minnesota.

Mitchell, J. P., Costa, P. A. and Waters, S. (1988) J. Aerosol Sci. 19, 213.

Ondov, J. M., Ragaini, R. C. and Biermann, A. H. (1978) Atmos. Environ. 12, 1175.

Pacyna, J. M., Vitols, V. and Hanssen, J. E. (1984) Atmos. Environ. 18, 2447.

Patterson, E. M. and Gillette, D. A. (1977) J. Geophys. Res. 82, 2074.

Puttock, J. S. (1981) Atmos. Environ. 15, 1709.

Rao, A. K. and Whitby, K. T. (1978) J. Aerosol Sci. 9, 87.

Sadavisan, S. (1978) Atmos. Environ. 12, 1677.

Shaw, G. E. (1986) J. Aerosol Sci. 17, 937.

Sverdrup, G. M. (1978) Atmos. Environ. 12, 2005.

Walsh, P. R., Rahn, K. A. and Duce, R. A. (1978) Atmos. Environ. 12, 1793.

Wesolowski, J. J. (1973) in Proc. Second Joint Conf. on Sensing of Environment Pollutants, p. 191. Instrument Society of America, Pittsburh, PA.

Whitby, K. T. (1973) VII ${ }^{\text {th }}$ International Conference on Nucleation, Leningrad, U.S.S.R.

Whitby, K. T. (1978) Atmos. Environ. 12, 135. 